\title{
Treatment response of sofosbuvir in HCV virus/ Helicobacter pylori co-infected patient a case report
}

\author{
Braira Wahid ${ }^{1}$ \\ (1) University of Management and Technology, Department of Life Sciences, Lahore, Pakistan
}

Date submitted:

Jun 11, 2019

Date accepted:

Oct 01, 2019

Online publication date:

December 15, 2019

\section{Corresponding Author: \\ Braira Wahid \\ University of Management and \\ Technology, Department of Life \\ Sciences, Lahore, Pakistan \\ brairawahid@gmail.com}

Keywords: DAA drugs, $\mathrm{HCV}, \mathrm{H}$. pylori, sofosbuvir, relapse.

\section{ABSTRACT}

Newly developed direct-acting anti-viral drugs act as a major breakthrough in the area of HCV therapeutics. Accumulating evidence suggest that more than $99 \%$ patients achieve sustained virological response after receiving sofosbuvir-based therapy. However, we observed the first case of DAA treatment failure in HCV patient who was co-infected with $\mathrm{H}$. Pylori.

\section{Introduction}

$\mathrm{HCV}$ is the leading cause of morbidity and mortality with global bioburden between 130-150 million infected people and approximately 700,000 deaths annually (1). The overall high prevalence of $\mathrm{H}$. pylori and $\mathrm{HCV}$ in developing world are major bacterial and viral human disease etiologies worldwide. Gram-negative bacillus $\mathrm{H}$. pylori has been associated with diverse spectrum of human enterohepatic disorders including mucosa-associated lymphoid tissue (MALT) lymphoma, peptic ulcer disease, gastritis, and gastric adenocarcinoma. Moreover, several evidences have reported the causal link of $\mathrm{H}$. pylori with variety of liver diseases such as HCV-related chronic hepatitis, cirrhosis, fibrosis, and hepatocellular carcinoma (2-4).

The recent development of interferon-free regimens has revolutionized the area of HCV therapeutics by increasing sustained virological response (SVR) in more than $80 \%$ patients. However, the cure rates are not high in cases of serious liver complications and co-infections. Some evidences suggest the poor efficacy of direct-acting anti-viral (DAA) drugs in co-infections. A recent study reported the reactivation of Hepatitis
$\mathrm{B}$ virus (HBV) infection in $\mathrm{HBV} / \mathrm{HCV}$ co-infected patient treated with sofosbuvir/ledipasvir (5). Likewise, findings of Perello et al., exhibited reactivation of herpesviruses in DAA treated patients $(6,7)$. At present, non-responsiveness and treatment failure towards DAA therapy have not been studied properly. Despite the strong association between $\mathrm{H}$. pylori and $\mathrm{HCV}$, no conclusive data are available regarding the efficacy and response of DAA in bacterial and viral co-infected patient. For effective eradication of $\mathrm{H}$. pylori, patients must be treated with (clarithromycin, amoxicillin, and omeprazole) for 2 weeks before starting DAA therapy (8). We experienced failed response to sofosbuvir and ribavirin in interferon ineligible $\mathrm{HCV} / \mathrm{H}$. pylori co-infected patient.

\section{Presentation of Case}

A 42-year old male patient from Lahore, Pakistan who had null response to prior interferon therapy and was ineligible for retreatment with interferon was referred by gastroenterologist to Genome Centre for Molecular Based Diagnostics \& Research laboratory in 2016. The patient was diagnosed with HCV 3a genotype after undergoing two general surgeries in 2011. The 
patient received pegylated interferon and ribavirin for 24 weeks in 2012 but experienced HCV relapse in 2016, four years after of interferon therapy. Laboratory evaluation revealed normal liver and spleen but mildly elevated liver function enzymes and bilirubin. His hemoglobin, total leukocytes count, and platelet count were below normal range. Viral load prior DAA treatment was $53,120 \mathrm{lU} / \mathrm{ml}$. During first three months of treatment with sofosbuvir (400mg) and ribavirin, viral load declined slightly whereas, mild increase in the HCV viremia was observed after the completion of six-months long treatment (Fig. 1).

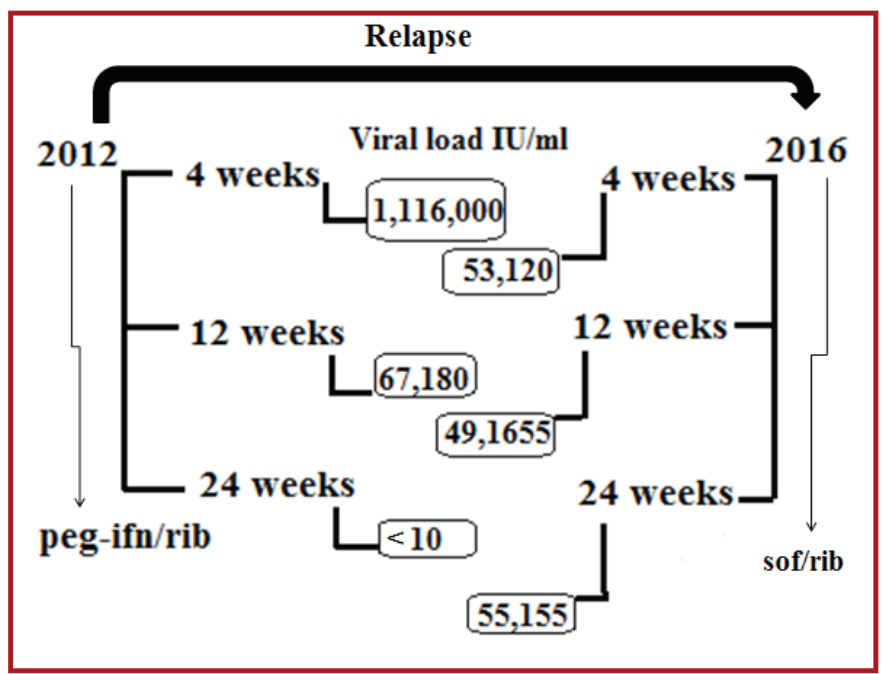

Figure 1. Treatment response towards peg-interferon/ribavirin therapy in 2012 and sofosbuvir/ribavirin therapy in 2016.

Patient was screened for other viruses (HBV, HEV, HAV \& HIV) common in Pakistani population to track the underlying cause of treatment failure. The PCR was negative for other hepatitis viruses and HIV moreover, ELISA was performed to detect anti-H. pylori because patient complained of bloating, nausea, and severe heartburn for three months. The confirmed diagnosis of $\mathrm{H}$. pylori infection in patient, indicates that $\mathrm{H}$. pylori is implicated in treatment failure towards both interferon-based and interferon-free therapies. The patient profile and case history is provided in table below.

\begin{tabular}{|c|c|}
\hline \multicolumn{2}{|c|}{$\begin{array}{l}\text { Table 1: Laboratory evaluation before and after DAA } \\
\text { therapy }\end{array}$} \\
\hline Variable & Measure \\
\hline Age & 42 \\
\hline Weight & 55 \\
\hline BMI & $7.9 \mathrm{~kg} / \mathrm{m} 2$ \\
\hline Genotype & $3 a$ \\
\hline ALP & $151 \mathrm{IU} / \mathrm{ml}$ \\
\hline ALT & $131 \mathrm{IU} / \mathrm{ml}$ \\
\hline AST & $106 \mathrm{IU} / \mathrm{ml}$ \\
\hline Hemoglobin & $11.6 \mathrm{~g} / \mathrm{dL}$ \\
\hline Platelet & $112 \times 103 / \mathrm{IL}$ \\
\hline Bilirubin & $0.4 \mathrm{mg} / \mathrm{dL}$ \\
\hline Total leukocyte count & 3900 (mcL) \\
\hline
\end{tabular}

\section{Discussion}

More than $50 \%$ of population is infected with $\mathrm{H}$. pylori and the presence of $\mathrm{H}$. pylori in liver material worsens condition of
$\mathrm{HCV}$ patients. In addition to this, H. Pylori is the universal problem in developing world that begins even from early childhood (9). Robust epidemiological data suggest high prevalence of $\mathrm{H}$. pylori in $\mathrm{HCV}$ infected cirrhotic patients because this bacteria has been reported to play an important role in the progression of liver disease. Reportedly, it has also been clarified that $\mathrm{H}$. pylori accerlates the progression of liver disease in HCV patients (10).

Few evidences have shown $\mathrm{H}$. pylori induced hepatotoxicity in vitro $(2,11)$.

Interferon-based treatment regimens is no longer the standard of care therapy since the development of interferon-free regimens i.e, interferon-free treatment or direct-acting anti-viral drugs (DAA). Large majority of patients have achieved sustained virolgoical response and have been successfully treated with DAA but herein, we observed a non-responder patient whose HCV RNA load didn't clear even after receiving 6 months long treatment with sofosbuvir and ribavirin. After investigating we found out that the patient had another bacterial co-infection that altered the treatment outcome (12). Therefore, the physicians belonging to developing world must monitor the patient for other common infections because the presence of co-infection alters the treatment outcome with DAA therapy.

\section{Conclusion}

In conclusion, the patient profile exhibited the involvement of $\mathrm{H}$. pylori in reduced efficacy of peg-ifn/ribavirin and sofosbuvir/ ribavirin in $\mathrm{HCV}$ infected patients. Hence, it might be useful to clear $\mathrm{H}$. pylori infection before starting HCV treatment. All HCV patients must be screened for identification of $\mathrm{H}$. pylori because of extremely high prevalence of this bacterial infection worldwide.

\section{Acknowledgments}

None

\section{Conflict of Interest}

The author declared nothing to disclose regarding conflict of interest with respect to this manuscript.

\section{Funding: None}

\section{References}

1. Lozano R, Naghavi M, Foreman K, et al. Global and regional mortality from 235 causes of death for 20 age groups in 1990 and 2010: a systematic analysis for the Global Burden of Disease Study 2010. The Lancet. 2013; 380(9859):2095-2128.

2. Rocha M, Avenaud P, Menard A, et al. Association of Helicobacter species with hepatitis $C$ cirrhosis with or without hepatocellular carcinoma. Gut. 2005; 54(3):396-401.

3. Waluga M, Kukla M, Żorniak M, Bacik A, Kotulski R. From the stomach to other organs: Helicobacter pylori and the liver. World J Hepatol. 2015; 7(18):2136-2146.

4. Dogan Z, Filik L, Ergül B, Sarikaya M, Akbal E. Association between Helicobacter pylori and liver-to-spleen ratio: a randomized-controlled single-blind study. Eur J Gastroenterol Hepatol. 2013; 25(1):107-110.

5. Fabbri G, Mastrorosa I, Vergori A, et al. Reactivation of occult HBV infection in an HIV/HCV Co-infected patient successfully treated with sofosbuvir/ledipasvir: a case 
report and review of the literature. BMC Infect Dis. 2017; 17(1):182-187.

6. Fernández-Carrillo $\mathrm{C}$, Londoño M-C, Arias-Loste T, et al. Reactivation of herpesvirus in patients with hepatitis $C$ treated with direct-acting antiviral agents. Clin Gastroenterol Hepatol. 2016; 14(11):1662-1666.

7. Takayama H, Sato T, Ikeda F, Fujiki S. Reactivation of hepatitis $B$ virus during interferon-free therapy with daclatasvir and asunaprevir in patient with hepatitis B virus/hepatitis C virus co-infection. Hepatol Res. 2015; 46(1):489-491.

8. Zandman D, Hahn W, Moss S. A Case of Persistent Helicobacter pylori infection occurring with anti-lgE immunosuppression. ACG Case Rep J. 2013; 1(1):16-18.

9. Bardhan PK. Epidemiological features of Helicobacter pylori infection in developing countries. Clin Infect Dis. 1997; 25(5):973-978.

10. Queiroz DMM, Rocha AMC, Rocha GA, et al. Association between Helicobacter pylori infection and cirrhosis in patients with chronic hepatitis $\mathrm{C}$ virus. Digestive Dis Sci. 2006; 51(2):370-373.

11. Taylor N, Fox J, Yan L. In-vitro hepatotoxic factor in Helicobacter hepaticus, $\mathrm{H}$. pylori and other Helicobacter species. J Med Microbiol. 1995; 42(1):48-52.

12. Foster GR, Pianko S, Brown A, et al. Efficacy of sofosbuvir plus ribavirin with or without peginterferon-alfa in patients with hepatitis $C$ virus genotype 3 infection and treatment-experienced patients with cirrhosis and hepatitis C virus genotype 2 infection. Gastroenterol. 2015; 149(6):1462-1470. 